\title{
ÁCIDO ASCÓRBICO NA ATENUAÇÃO DOS EFEITOS DO ESTRESSE SALINO EM AMENDOIZEIRO
}

José Clebson Barbosa Lúcio; ${ }^{1}$ Rita de Cássia Alves²; Kevein Ruas de Oliveira³; Jeferson dos Santos da Silva $^{4}$; Emilaine da Rocha Prado ${ }^{5}$; Willians César Carrega ${ }^{6}$; Priscila Lupino Gratão

${ }^{1}$ Mestrando em Agronomia (Produção Vegetal), FCAV/UNESP, Jaboticabal, SP, clebson_jcbl.praxedes@hotmail.com; ${ }^{2}$ Doutoranda em Agronomia (Produção Vegetal), FCAV/UNESP, Jaboticabal, SP; ${ }^{3}$ Mestrando em Agronomia (Produção Vegetal), FCAV/UNESP, Jaboticabal, SP; ${ }^{4}$ Graduando em Agronomia FCAV/UNESP, Jaboticabal, SP; ${ }^{5}$ Graduanda em Agronomia FCAV/UNESP, Jaboticabal, SP; ${ }^{6}$ Doutor em Agronomia (Produção Vegetal), FCAV/UNESP, Jaboticabal, SP; ${ }^{7}$ Docente da FCAV/UNESP, Jaboticabal, SP.

RESUMO: O presente estudo teve por objetivo avaliar o efeito benéfico da aplicação exógena de AsA em amendoinzeiro sob estresse salino, através da determinação de respostas fisiológicas e dano oxidativo. O experimento foi realizado em DIC, num esquema fatorial $2 \times 2$, composto por duas concentrações de ácido ascórbico (AsA) (0 e $50 \mathrm{mM}$ ) e duas concentrações de cloreto de sódio $(\mathrm{NaCl})$ (0 e $50 \mathrm{mM}$ ). A salinidade foi aplicada diariamente junto com a irrigação e o AsA foi aplicado duas vezes na semana por via foliar, sendo a unidade experimental um vaso com capacidade para 4 litros de solo. Aos 40 dias após a germinação avaliou-se os parâmetros de conteúdo de clorofila total; carotenóides e MDA, além de massa seca da parte aérea, raiz e total. Com base nos resultados, a aplicação de AsA exógena alivia os efeitos deletérios causados pela salinidade através do incremento de pigmentos fotossintéticos e da redução dos danos oxidativo, refletindo em um maior crescimento de parte aérea do amendoinzeiro.

Palavras-chave: Arachis hypogaea L., salinidade, estresse oxidativo.

\section{INTRODUÇÃO}

A cultura do amendoim (Arachis hypogaea L.) é uma das plantas oleaginosas mais produzidas no Brasil, onde a produção esperada para a safra 2017/2018 é de 515,4 mil toneladas, sendo o estado de São Paulo o maior produtor (CONAB,2018). No entanto, para o bom rendimento da cultura é necessário que as condições ambientais sejam favoráveis, uma vez que, os diversos estresses abióticos provocam alterações fisiológicas e bioquímicas reduzindo diretamente o crescimento das plantas (PONTIGO et al. 2017, ALVES et al. 2018). Dentre os estresses abióticos, o salino é caracterizado como um dos mais problemáticos, pois limita o crescimento e a absorção de nutrientes pelas plantas (ALVES et al. 2018).

Os sintomas provocados pelo estresse salino refletem mudanças morfológicas, fisiológicas e bioquímicas das plantas, tais como, diminuição na taxa fotossintética, deficiente absorção de nutrientes, indução da peroxidação lipídica através da superprodução de espécies reativas de oxigênio 
(ERO) nas células vegetais, e inibição de sistemas enzimáticos (YASAR et al. 2016, ALVES et al., 2018).

Em vista disso, desenvolver pesquisas buscando estratégias de manejo que possibilite maior tolerância das plantas ao estresse salino é de fundamental importância. Assim, o uso de ácido ascórbico (AsA) exógeno pode ser um potente atenuador de estresse salino, induzindo síntese protéica e produzindo compostos de defesa química, além de ser um dos antioxidantes mais potentes, pois pode diminuir a síntese de ERO, aumentando assim a tolerância ao estresse (ALHASNAWI et al. 2016).

Diante da importância que esta cultura assume, este estudo teve por objetivo avaliar o efeito benéfico da aplicação exógena de AsA em amendoinzeiro sob estresse salino, através da determinação de respostas fisiológicas e danos oxidativos.

\section{MATERIAL E MÉTODOS}

O trabalho foi realizado na Faculdade de Ciências Agrárias e Veterinárias, UNESPUniversidade Estadual Paulista, Campus de Jaboticabal - SP a céu aberto. Sementes de amendoinzeiro da cultivar IAC-O15 foram utilizadas para o desenvolvimento do trabalho.

Os tratamentos foram formados pela combinação de duas concentrações de cloreto de sódio $(\mathrm{NaCl})(0$ e $50 \mathrm{mM})$ e duas concentrações de ácido ascórbico (AsA) (0 e $50 \mathrm{mM})$. A aplicação do $\mathrm{NaCl}$ ocorreu diariamente junto com a irrigação, já a aplicação de AsA ocorreu duas vezes por semana sendo aplicado via foliar. O experimento foi realizado, utilizando o delineamento inteiramente casualizado, em esquema fatorial $2 \times 2$, com quatro repetições, onde a unidade experimental foi representada por um vaso com capacidade para 4 litros de solo.

Quando as plantas atingiram 40 dias após a germinação, estas foram coletadas e avaliadas quanto aos seguintes parâmetros: conteúdo de clorofila total; carotenóides; massa seca da parte aérea, raiz e total; e conteúdo de malondialdeído (MDA). Após a coleta dos dados foi realizada a análise estatística pelo teste de comparação de médias, aplicando-se o teste Tukey a 5\% de probabilidade, utilizando Software Sisvar 5.3 (FERREIRA, 2011).

\section{RESULTADOS E DISCUSSÃO}

Para os resultados de clorofila total e carotenóides foi observado efeito significativo apenas para as concentrações de AsA (0 e $50 \mathrm{mM})$. Para ambas as concentrações de $\mathrm{NaCl}(0$ e $50 \mathrm{mM})$ o maior conteúdo de clorofila ocorreu em $50 \mathrm{mM}$ de AsA, correspondendo a $42 \%$ e $34,3 \%$ de incremento respectivamente para ambos os pigmentos nas condições de salinidade e AsA (Fig. 1A e 1B). Para o MSPA, foi observado efeito significativo do AsA entre e dentro das concentrações de $\mathrm{NaCl}$, sendo que em $0 \mathrm{mM}$ de $\mathrm{NaCl}$ houve incremento de 19,13\% e em $50 \mathrm{mM}$ de $\mathrm{NaCl}$ houve incremento de $8,7 \%$ da MSPA para $50 \mathrm{mM}$ de AsA. 
Comparando-se as concentrações de AsA entre as concentrações de $\mathrm{NaCl}$ observa-se que a maior MSPA ocorreu em $0 \mathrm{mM}$ de $\mathrm{NaCl}$ independente da concentrações de AsA (Fig. 1C). Já para a MSR foi observado que a salinidade $(50 \mathrm{mM}$ de $\mathrm{NaCl})$ reduziu a MSR quando usou-se a concentração de $50 \mathrm{mM}$ de AsA (Fig. 1D).

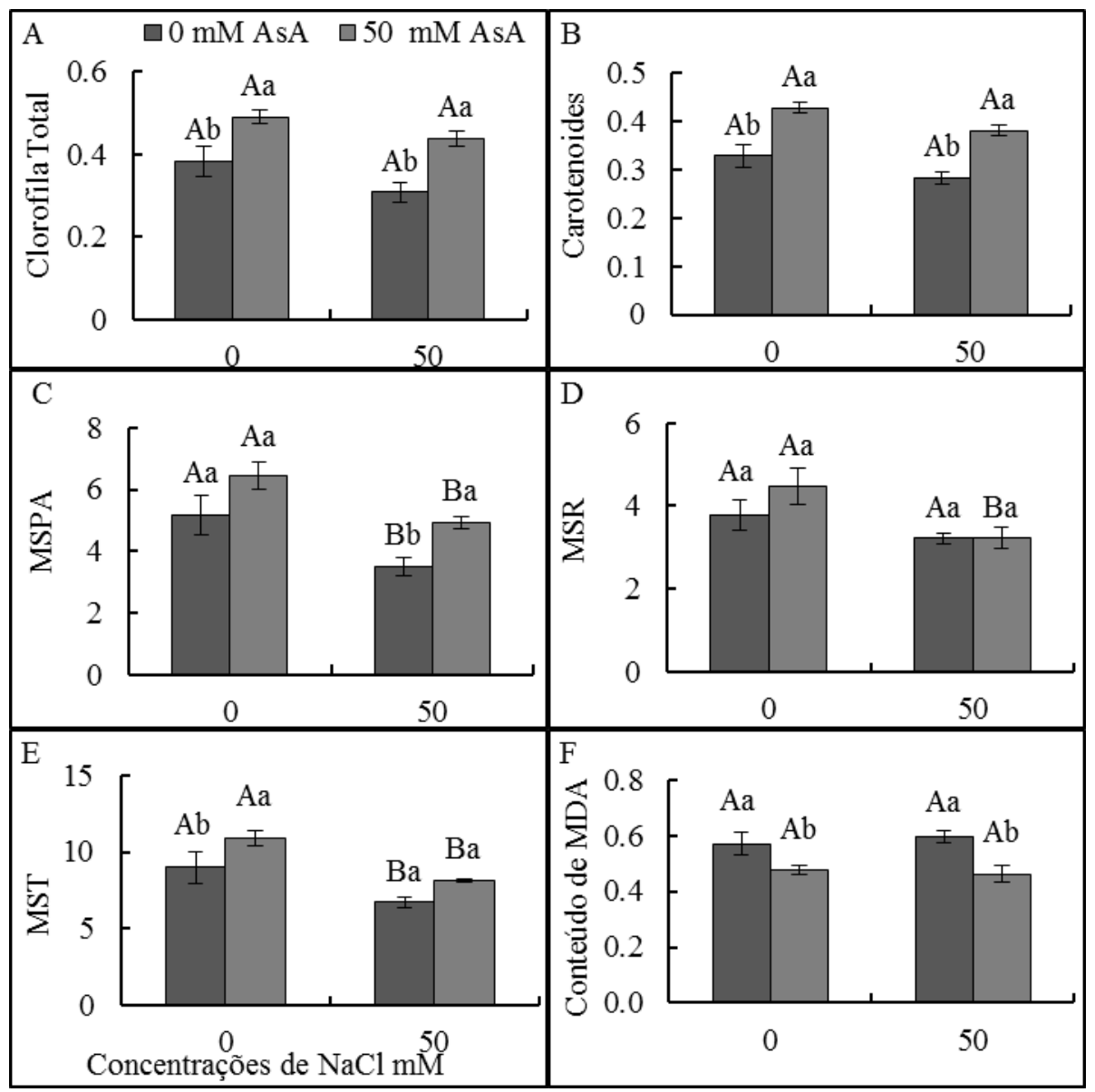

Figura1. Conteúdo de clorofila total (A) e carotenoides (B) ( $\mu \mathrm{g} \mathrm{mg}^{-1}$ massa fresca); Massa seca da parte aérea $(\mathrm{C})$, raiz (D) e total (E) (g planta $\left.{ }^{-1}\right)$; conteúdo de MDA (F) ( $\mu \mathrm{mol} \mathrm{mg}^{-1}$ massa fresca). Letras minúsculas comparam as concentrações de AsA entre si dentro das concentrações de $\mathrm{NaCl}$, letras maiúsculas comparam as concentrações de AsA entre as concentrações de $\mathrm{NaCl}$. Lestras iguais não diferem entre si estatisticamente ao nível de 5\% de probabilidade pelo teste de Tukey.

De acordo com os resultados para a MST, houve efeito significativo tanto para o $\mathrm{NaCl}$ quanto para o AsA, onde dentro de $0 \mathrm{mM}$ de $\mathrm{NaCl}$ foi observado maior MST com $50 \mathrm{mM}$ de AsA, não havendo diferença dentro de $50 \mathrm{mM}$ de $\mathrm{NaCl}$. Entretanto, observou-se que houve redução da MST em $50 \mathrm{mM}$ de $\mathrm{NaCl}$ independente da concentração de AsA (Fig. 1E).

Para peroxidação lipídica expressada pelo conteúdo de MDA, foi observado efeito significativo do AsA apenas dentro das concentrações de $\mathrm{NaCl}$, onde o AsA $(50 \mathrm{mM})$ reduziu o conteúdo de MDA dentro de ambas as concentrações de $\mathrm{NaCl}$ (0 e 50 mM (Fig. 1F). Nas condições de salinidade o AsA promoveu uma redução do conteúdo de MDA de 20,83 e 21,6\% em 0 e 50 mM de $\mathrm{NaCl}$, respectivamente. 
O excesso de sal no solo e na água pode causar efeitos deletérios às plantas, como inibição da fotossíntese, redução da transpiração foliar, desequilíbrio iônico e aumento na produção de espécies reativas de oxigênio, gerando estresse oxidativo e consequentemente redução do crescimento (ALVES et al., 2018). Visto que o AsA desempenha um papel extremamente importante contra o estresse salino por meio da degradação direta das ROS (OZGUR et al., 2013), a aplicação de AsA exógeno proporcionou aumento do conteúdo total de clorofilas e carotenóides (Fig. 1A e 1B), indicando ação positiva do AsA na atenuação do estresse salino, uma vez que, a maior síntese de clorofila na fase inicial de crescimento do amendoim é vista como uma boa medida da capacidade das plantas em tolerar o estresse salino (ARUNYANARK et al., 2008). Além disso, o aumento de carotenoides também desempenha um papel protetor como antioxidante molecular por meio da degradação do oxigênio singleto (GOMES et al. 2017), de forma que o aumento do teor de carotenóides sob estresse salino contribui para uma menor produção de ROS e consequentemente menor destruição de pigmentos fotossintéticos (CHAKRABORTY et al., 2015). Neste mesmo sentido, o conteúdo de MDA em menores proporções, com a aplicação de AsA (Fig. 1F), reafirma a ação atenuadora do AsA sobre o estresse salino.

Sabe-se que o crescimento da parte aérea é mais sensível do que o crescimento radicular em condições de seca e de estresse salino (KAVAS et al., 2015). No presente estudo foi observado que o AsA promoveu incremento da MSPA em ambas as concentrações de $\mathrm{NaCl}$ (Fig. 1 C). Em concordância com o exposto acima, a MSR do amendoim não sofreu alterações quando exposta a salinidade (Fig. 1D), e devido a isto não foi possível verificar aumento da MST em condições de salinidade (Fig. 1E). Segundo WILLADINO e CÂMARA (2010), aspectos como as características da planta, incluindo identidade do órgão ou tecido, estágio de desenvolvimento e genótipo influenciam a resposta ao estresse.

De maneira geral os resultados acima mostram que o uso de AsA exógeno promoveu incremento dos pigmentos fotossintéticos e fotoprotetores com consequente redução da peroxidação lipídica, fatores que agem diretamente na eficiência do crescimento vegetal, corroborando com a maior MSPA (BARUS et al., 2015). 


\section{CONCLUSÃO}

A aplicação de AsA exógena alivia os efeitos deletérios causados pela salinidade através do incremento de pigmentos fotossintéticos e da redução dos danos oxidativo, refletindo no maior crescimento de parte aérea do amendoinzeiro.

\section{REFERÊNCIAS BIBLIOGRAFICAS}

ALHASNAWI, A. N.; RADZIAH, C.M.Z.; KADHIMI, A.A.; ISAHAK, A.; MOHAMAD, A.; YUSOFF, W. M. WEnhancement of antioxidant enzymes activities in rice callus by ascorbic acid under salinity stress. Biologia Plantarum, 13: 1-5, 2016.

ALVES, R. C.; MEDEIROS, A. S.; NICOLAU, M. C. M.; PIZOLATO NETO, A.; OLIVEIRA, F. A.; LIMA, L. W.; TEZOTO, T.; GRATÃO, P. L. The partial root-zone saline irrigation system and antioxidant responses in tomato plants. Plant Phisiology and Biochemistry, 127: 366-379, 2018.

ARUNYANARK, A.; JOGLOY, S.; AKKASAENG, C.; VORASOOT, N.; KESMALA, T.; RAO, R. C. N.; WRIGHT, G. C.; PATANOTHAI, A: Chlorophyll stability is an indicator of drought tolerance in peanut. Journal of Agronomy and Crop Science 194, 113-125, 2008.

BARUS, W. A.; RAUF, A.; ROSMAYATI, AND HANUM, C. Improvement of salt tolerance in some varieties of rice by ascorbic acid application. International Journal of Science and Research, 4: 2277-8616, 2015.

CHAKRABORTY, K.; SINGH, A. L.; KALARIYA, K. A.; GOSWAMI, N.; ZALA, P. V. Physiological responses of peanut (Arachis hypogaea L.) cultivars to water deficit stress: status of oxidative stress and antioxidant enzyme activities. Acta Botanica Croatica, 74(1), 123-142, 2015.

CONAB-companhia Nacional de Abastecimento. Acompanhamento da safra brasileira: Grãos. (ed. 9) Brasília, v. 5, 178p., 2018.

FERREIRA, D. F. Sisvar: a computer statistical analysis system. Ciência Agrotecnologia, 35, 10391042, 2011.

GEST N.; GAUTIER H.; STEVENS R. Ascorbate as seen through plant evolution: the rise of a successful molecule. Journal of Experimental Botany 64:33-53, 2013.

GOMES, M. A. C.; PESTANA, I. A.; SANTA-CATARINA, C.; HAUSER-DAVIS, R. A.; SUZUKI, M. S. Salinity effects on photosynthetic pigments, proline, biomass and nitric oxide in Salvinia auriculata Aubl.. Acta Limnologica Brasiliensia, 29: 1-13, 2017.

KAVAS, M.; AKÇA, O. E.; AKÇAY, U. C.; PEKSEL, B.; EROĞLU, S.; ÖKTEM, H. A.; YÜCEL, M. Antioxidant responses of peanut (Arachis hypogaea L.) seedlings to prolonged salt-induced stress. Archives of Biological Sciences, 67(4), 1303-1312, 2015.

OZGUR R,; UZILDAY B.; SEKMEN AH.; TURKAN I. Reactive oxygen species regulation and antioxidant defence in halophytes. Functional Plant Biology 40:832-847, 2013. 
PONTIGO, S.; GODOY, K.; JIMÉNEZ1, H.; GUTIÉRREZ-MORAGA, A.; MORA, M. L.; CARTES, P. Silicon-Mediated Alleviation of Aluminum Toxicity by Modulation of $\mathrm{Al} / \mathrm{Si}$ Uptake and Antioxidant Performance in Ryegrass Plants. Frontiers in Plant Science, 8: 1-15, 2017.

WILLADINO, L.; CAMARA, T. R.; Tolerância das plantas à salinidade: aspectos fisiológicos e bioquímicos. Enciclopédia biosfera, v. 6, n. 11, p. 1-23, 2010.

YASAR, F., UZAL, O., YASAR, O. Antioxidant enzyme activities and lipidperoxidation amount of pea varieties (pisumsativum sp. arvense L.) under salt stress. Fresenius Environmental Bulletin, 5: $37-42,2016$. 